\title{
Yumurta tavuğu rasyonlarında enzim, probiyotik ve antibiyotik kullanılması*
}

\section{Sakine YAI.ÇIN ${ }^{1}$, Berrin KOCAOĞLU GÜÇL $\ddot{U}^{2}$, Fatma KARAKAŞ OĞUZ ${ }^{3}$, Suzan YAIÇIN}

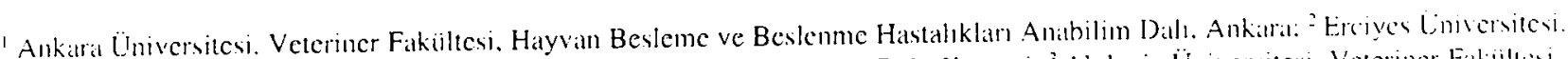

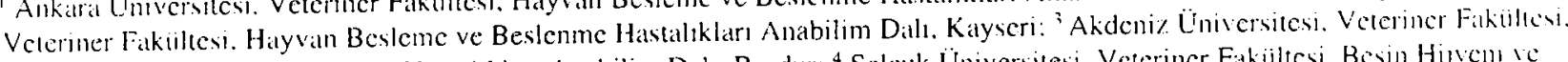
Hiyvan Besleme ve Beslemme Histalıklan Anabilim Dalı, Burdur; ${ }^{4}$ Selçuk Üniversitesi. Veteriner Fatkïltesi. Besin Hijyem ve Tcknolojisi Anabilim Dalı. Konya

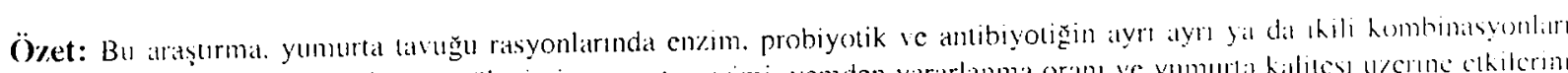





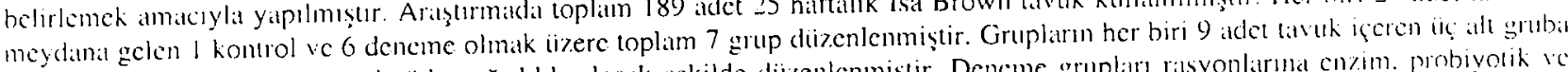

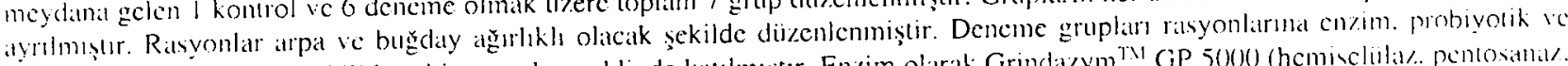

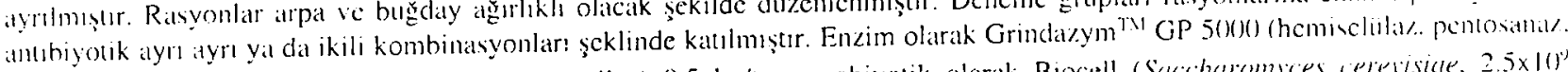

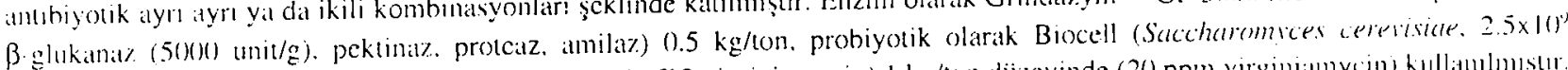

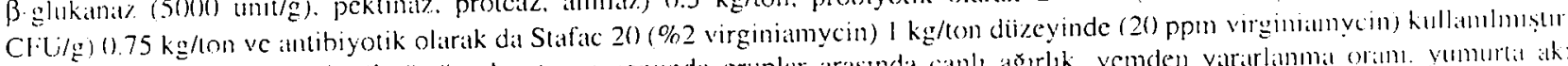

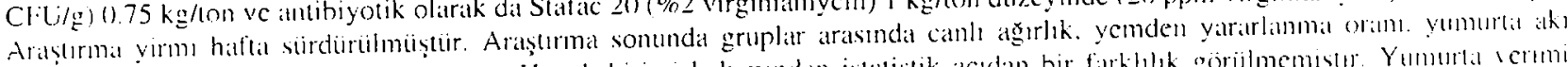

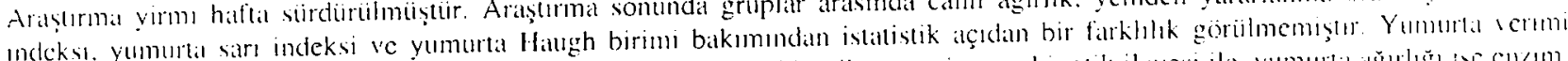

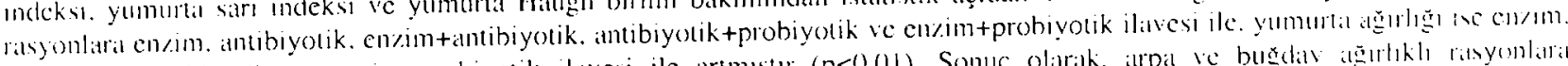



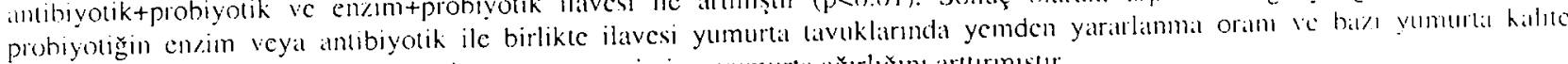

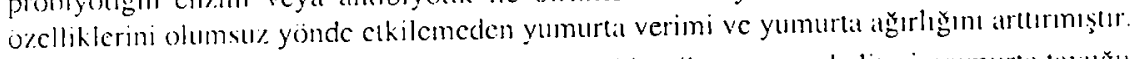

Anthtat kclimeler: Antibiyotik, cnzim. probiyotik. yumurta kaditesi. yumurta tavuğ yumurta verimi

\section{The usage of enzyme, probiotic and antibiotic in laying hen rations}

Summary: This study was carried out to determine the effects of the usige of enzyme. probiotic or antibiotic atouc or in combination in the rations on live weight. feed consumption. egg production. feed efficiency and ege quality of laving hens. A lutal



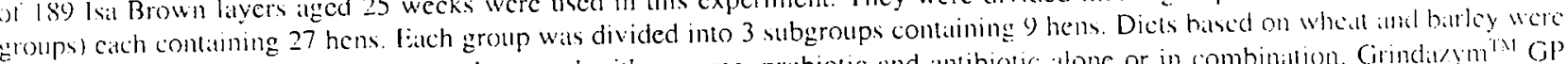

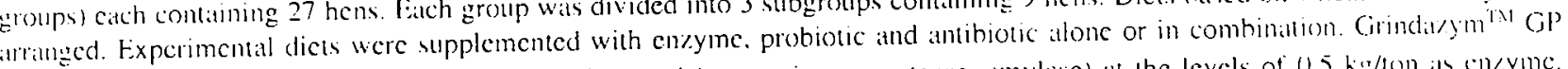

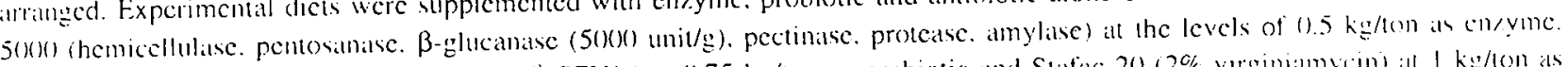

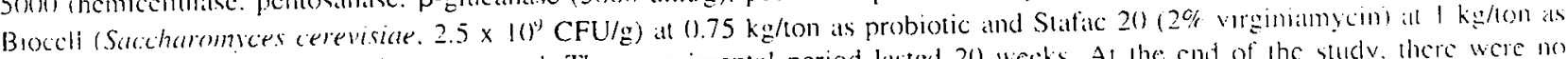
anlibiolic 20 ppm virginianyein) were used. The experimental period lasted 20 wecks. At the end of the study. there were an


production was significintly increased $(p<0 .(3)$ ) with the supplementation of enzyme. intibiotic. entymetantihiotic.

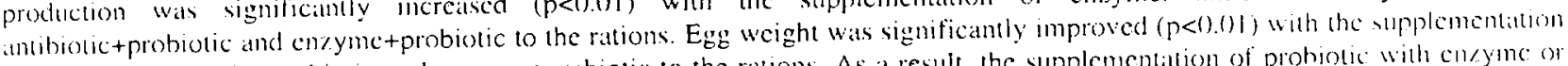
of ensme. imtibiolictprobiotic and enzyme+probiotic to the rations. As a result. the supplementalion of probiotic with curyme or

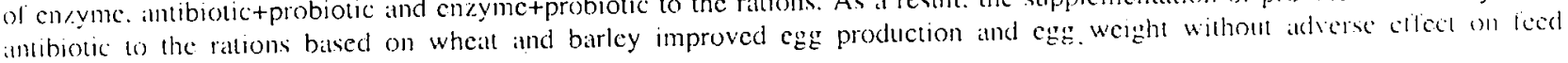
efliciency and some ege qualily charicteristics.

Key words: Antibiotic. cag production. cgg quality, enzyme. litying hen. probiolic

\section{Giriş}

Son yllarda yemlerdeki hesin maddelerinin ya. rarlanılabilirliğginde sağlanan artışlar, özellikle kanatlı endijstrisinde verim artı̧n da beraberinde getirniş̧tir. Kamatlı rasyonlarında encrji kaynağ olarak yuiksck oranda misır kullamilmaktadır. Misırin yeterli olmadığ dönemlerde ise kanalls rasyonlarma misır yerine sorgum, bug ğclay ve arpa gibi ham maddeler katılmaktadır.
Buğday ve arpann bileşimindeki çärinthilen $\mathrm{ni}$ sasta tabiatunda olmayan polisakkarilles sindirim içeriğinin vizkositesini arturarak. hagrsakta besin madde emiliminin azalmasma neden olur. Bu durum da verimin düşmesine, yapışkan dışkı oluşumuna ve kirli jumurla uireciminde artışa yol açar (7.12,40). Kanall heslemede buğday ve arpaya dayah rasyonlar kullanıldığanda yem-

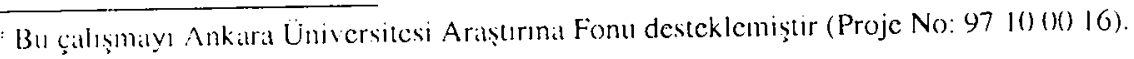


den yarartanmay' arturmak için rasyonlara çeşitli yem katkı maddeleri ilave edilmektedir.

Barı araşturicılar $(15.17,23,29.30)$ rasyonlara enzim ilavesinin yumurta lavuklarunda yunurta verimi, yem üiketimi, yemden yararlanma oranı, yumurta ağırlığı, yumurta kunlma mukavemeti ve Haugh birimini etkilemedigini bildirirlerken. Nasi (28) ve Aimonen ve Nasi (2) yumurlat verimini. Aimonen ve Nasi (2) yemden yararlanma oranını, Brufau ve ark. (8) yumurta ağırlığını olumlu yönde elkilediğini kaydetmişlerdir. Wyatt ve Goodman (39), besin maddelerinin yiiksek diizeyde gereksinim dujudduğ maksinum verim döneminde enzim ilavesinin yararlı olabileceğini rapor emişlerdir.

Nahashon ve ark. (27) yaptıkları bir araştrmada, rasy onlara probiyotik ilavesinin yumurta verimi, yem tiiketimi. yenden yararlanma oranı, yumurta Haugh birimi ve yumurta kabuk kalınlığı bakımından farklılık yaratmadığm. yumurla ağırlığgnda istatistik açıdan $(\mathrm{p}<0.05)$ artış sağladığmı. Krueger ve ark. (24) ise probiyoliğin yumurta verimi ve yenden yararlanma oranını olumlu yönde etkilediğinj kaydetmişlerdir.

Vukic Vranjes ve Wenk (37), arpaya dayalı rasyona enzim ilavesinin enerji ve organik madde degerlendirilmesini olumlu yönde etkilediğini, antibiyotik ilavesinin isc enerji ve besin madde değgerlendirilmesi bakımundan farklılık olışturnıdığını saptamışlardır. Yem tüketimi. yumurta verimi ve yemden yararlanma oranının ise rasyoni enzim ve/veya antibiyotik ilavesinden etkilenmediği hildirilmişlir.

Bu araşurma: enzin, probiyotik ve antibiyotiklerin ayn ayrı ya da birlikte arpa ve buğday ăğrlıklı rasyonlarda kullanımlarmnın yumurta tavuklarında canlı ağır- lık. yumurta verimi, yem tïketimi. yemden yararlanmal oran ve ba7ı yumurta kalite öellikleri iizrine ctkilerini incelemek amaciyla yapılmışır

\section{Materyal ve Metot}

Araştırmada Loplam 189 ade 25 halfialik Isal Brown tavuk kullanılmışur. Tavuklar her birinde 3 adel olacak şekilde 63 kafese $(530 \mathrm{~cm}=/$ tavuk) rasgele diağululmuşur. Araşturmada her hiri 27 adet lavuklan meydana gelen 1 kontrol ve 6 deneme olmak iizere toplam 7 grup dii zenlenmiştir. Gruplarmn her hiri 9 adel lav uk içeren iiç alı

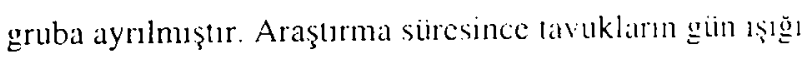
ile birlikte 17 saiat 1 şıtan yararlanmalan sağ

Araşurmada kontrol grubu lasyonu arpa-buğday ağırlıklı olarak ve enzim, probiyolik ve antihiyolik kapsamayacak şekilde hazırlanmıştır. Gruplardaki düren Tablo l'de. rasyonlarm bileșini ise Tablo 20de goos terilmektedir. Rasyonlar izokalorik ve izonitrojenik olitcak şckilde hazırlanmuştır. Araşurmada enzim olarak Grindazym ${ }^{\mathrm{T} 1}$ GP 5000 (hemiseliilay. pentosana\%. $\beta$ glukana\% (5000 unit/g), pektina\% protea\% annilaz) $0.5 \mathrm{~kg} /$ ton diizeyinde, probiyotik olarak Biocell (Saccharomyces

Tablo 1. Araştırma gruplarmmun diazcni.

Table 1. The design of experimental groups.



Tablo 2. Araştııma rasyonunum bileșimi.

Table 2. The composition of experimental ration.

\begin{tabular}{|c|c|c|c|}
\hline Yem maddesi & $\%$ & Kimyasal bilcşimi & \\
\hline Bugdaly & 51 & Kuru madde, \% & 91.40 \\
\hline Arpal & 18 & Haan protcin. \% & 16.60 \\
\hline Soya kijspesi & 9.4 & Ham yag. $\%$ & 3.42 \\
\hline Taun yaghli soyit & 9.0 & Ham seliiloz. \% & 3.17 \\
\hline Et kemik unu & 4.0 & Ham kiil. \% & 10.43 \\
\hline Kircç laşl & 7.2 & Azotsuz öz madde. \% & 57.78 \\
\hline Dikitlsiyum fosfat & 0.5 & Kalsiyum, \% & 3.42 \\
\hline Tuz: & 0.25 & Fosfor, \% & $0.60)$ \\
\hline Vitamin karmasıl & 0.20 & Melabolize olabilir enerji. $\mathrm{kcal} / \mathrm{kg}$ & 2684 \\
\hline Mincral kitmats!? & 0.15 & & \\
\hline DL-metiyonin & 0.20 & & \\
\hline Kolin kloriir & 0.10 & & \\
\hline
\end{tabular}


g $\mathrm{B}_{2}$ vit. $2 \mathrm{~g} \mathrm{~B}_{6}$ vit. $15 \mathrm{mg} \mathrm{B}_{12}$ vit, $2 \mathrm{~g} \mathrm{~K}_{3}$ vit, $1.5 \mathrm{~g}$ folik asit. $30 \mathrm{~g}$ niasin. $8 \mathrm{~g}$ kalsiyum D-pantotenat bulummaklakdr.

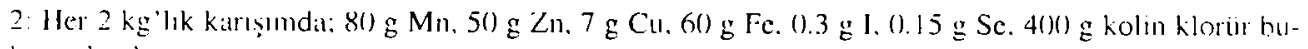
lunmaktadir.

3. Besin matde bileşimi ^OAC (4)'ye görc. ME dizeyi isc TSE (36) ye göre beliricnmiștir. 
(erevisicue. $\left.2.5 \times 10^{\prime \prime} \mathrm{CFU} / \mathrm{g}\right) 0.75 \mathrm{~kg} /$ ton düzeyinde ve antibiyotik olarak da Stafac 20 (\%2 virginiamycin) $1 \mathrm{~kg} /$ 10 dïzeyinde (20 ppm virginiamycin) kullanılmıştır.

Hayvanlara yem ad libitum verilmiştir. Her bir alt grupta bulunan tavuklar grup yemlemesine tabi tutulmuştur. Otomatik suluklar kullanılarak hayvanların önïnde sürekli su bulunmalsı sağglanmışur. Araşurma 20 halfia sürduirüilnüuşüir

Araşurmada kullanılăn yem maddelerinin ve rasyonlaru besin madde miktarlar AOAC (4)'de bildirilen analiz. metotlarma göre belirlenniştir. Mctabolize olabilir enerji diizeylerinin hesaplanmasmda ise TSE (36)'nin önerdiğ formiil kullanılmıştır.

Araşırmanın başında ve sonunda tavuklar tek tek tartularak canlı ağırlıklar belirlenmiştir. Iki haftada bir yapulan tartumlarla yem tiiketimi alt grubun ortalaması olarak tesbit edilmiş̧ir.

Gruplarda giinliuk yunurta verimi kaystlar tuıulnışıur. Çallak-kırık ve kirli yumurta sayıları da kaydedilmiştir. Yumurtalar haftada bir kere oda sicaklığğnda 24 silat bekletildikton sonra tartılıp ağırlıkları saplammışur. Yenden yararlanma oranı, bir düzine yumurta için lüketilen yem miktarı ve bir $\mathrm{kg}$ yumurta için tüketilen yem miktarı olarak bulunmuştur.

Bes haltada bir kere ise her bir gruptan elde edilen 1.5 adel yumurtada kurılma mukaveneli. yunurta akı in deksi, yumurta sar incleksi. Haugh birimi ve yumurta kabuk kalınlığ belirlenmiştir (10). Ayrıca, yumurtalarda kan lekcleri de tespit edilmişuir.

Gruplara ail islatistik hesaplamalar ve grupların orlalanı değcrlcri arasındaki farklılıkların önemliliğ̣ için variyans analiz melodu, gruplar arasındaki farkın öncm- lilik kontrolii için de Duncan testi uyg̨ulanmuşur (34). Istatistik analizler SPSS 10.0 (Inc.. Chicilgo. IL. USA) programına göre yapılmıştır.

\section{Bulgular}

Araştırma süresince gruplarda älüm go golenmemiştir Gruplardaki lavuklarm ortalama canlı ağ lüketimi degerleri Tablo 3 'de. yumurta verimi ve yu murta ağırlığ ise Tablo 4'de göstcrilmekledir. Araşurma sonunda ortalama canl ağrlık bakımından gruplat arasında istatistik açıdan önemli bir farklılık gaijzlenmemişlir. Kontrol grubu (1. grup) ve sadece probiyolik ilaveli rasyonu tüketen 4. grupta yumurta verims diğer gruplatrdan daha diişiik bulunmuştur $(p<0.01)$. Grupların yemden yalrarlanma değerleri Tablo 5 de. bazı yumurla kalite ozclliklerine at ortalama değerler ise Tahlo $f^{\circ}$ da verilmektedir. Bir kg yumurta için tüketilen yem mikları 1. $2,3,4,5.6$ ve 7 . gruplarda sirasiyla 2.36. 2.21. 2.26. $2.30,2.19,2.15$ ve $2.14 \mathrm{~kg}$ olup gruplar arasindaki larklılıklar önemsiz bulunmuştur. Yumurta akı indeksi. yumurta san indeksi ve yumurta Haugh hirimi bakımundan gruplar arasında istalistik açıdan bir latuklılık gioriilmemiştir. Gruplar arasında çatlak-kırık yumurı say1s1, kirli yumurta sayısı ve yumurtada kan lekesi balkımından istatistik değerlendirmeyc alınacak bil larklılık gö̌lenmemiştir.

\section{Tartışma ve Sonuç}

Arpa ve buğgday ağgrlıklı yumurta tavuğgu rasyonlarunda enzins, probiyotik ve antibiyotiğhn ayrs aym ya da birlikte kullanılması, yunurta lavuklarmda 20 halialık araşurma sonunda canlı ağ̀rılık bakmmundan istatıstik açı

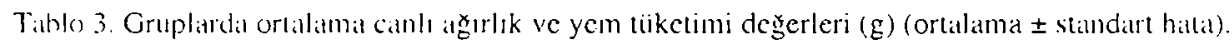

Table 3. Mean values of live weight and fecd consumption in groups $(\mathrm{g})$ (mean \pm statdard cror).

\begin{tabular}{|c|c|c|c|c|c|c|c|c|}
\hline \multirow[b]{2}{*}{ Halfial } & \multicolumn{7}{|c|}{$\mathrm{Grupl} a r$} & \multirow[b]{2}{*}{$F$} \\
\hline & $\begin{array}{c}1 \\
\text { Kontrol }\end{array}$ & $\begin{array}{c}2 \\
\text { Enzim }\end{array}$ & $\frac{3}{\text { Antibiyotik }}$ & $\begin{array}{l}4 \\
\text { Probiyotik }\end{array}$ & $\begin{array}{l}5 \\
\text { Enzins + } \\
\text { intibiyotik }\end{array}$ & $\begin{array}{l}\quad 6 \\
\text { Antibiyotik + } \\
\text { probiyotik }\end{array}$ & $\begin{array}{l}7 \\
\text { Enyim + } \\
\text { probiyolik }\end{array}$ & \\
\hline \multicolumn{9}{|c|}{ Calıl ، } \\
\hline$\therefore$ & $1778 \pm 28$ & $1 \times 13 \pm 20$ & $1760 \pm 22$ & $1751 \pm 29$ & $1694 \pm 24$ & $1751 \pm 2.5$ & $17+5=22$ & 212 \\
\hline 46 & $1943 \pm 50$ & $20164 \pm 36$ & $1992 \pm 29$ & $\mid 961 \pm 29$ & $1962 \pm 3 x$ & $\mid Y(x \pm 31$ & $192^{-}=3 i$ & $2.11=$ \\
\hline \multicolumn{9}{|c|}{ 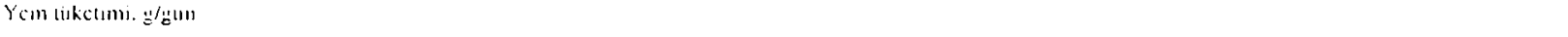 } \\
\hline 26.29 & $113.8 \pm 16 \mathrm{hc}$ & $122.1 \pm 1.9 \mathrm{a}$ & $1211.7 \pm 1.2 a$ & $107.7 \pm 0.41$ & $117.3 \pm 203,1 h$ & $114.3 \pm 1.7 h_{c}$ & $111 x=21 \mathrm{l}$ & $4.2 x$ \\
\hline $301-3.3$ & $1155 \pm 44$ & $1212 \pm 3.4$ & $126.3 \pm 3.8$ & $121.3 \pm 1.9$ & $116.9 \pm 2.3$ & $116.0 \pm=3.1$ & $1174 \pm 119$ & 163 \\
\hline 34.37 & $125.6 \pm 4.1$ & $124.7 \pm 2.5$ & $1.30 .2 \pm 4.1$ & $130.8 \pm 1.8$ & $129.1 \pm 19$ & $126.4 \pm 3 x$ & $129 ?=1: 8$ & 4.31 \\
\hline $3 x-4 \mid$ & $13.7 \pm 20 \mathrm{a}$ & $128 . x=4 \mathrm{Jab}$ & $1319 \pm 06 a h$ & $126.8+17 \mathrm{hc}$ & $125.9 \pm 12 \mathrm{hc}$ & $1219 \pm 40$ & $1201.7 \pm 22$ & +35 \\
\hline $42-45$ & $13.7 \pm 2.4$ & $1347 \pm 2.5$ & $131.8 \pm 20$ & $129.3 \pm 2.5$ & $126.7 \pm 1.6$ & $128.3 \pm 2.9$ & $129 \geq \pm 13.8$ & $! \times 5$ \\
\hline $26-45$ & $124.8 \pm 11.8 \mathrm{ah}$ & $127.3=1 . x_{i 1}$ & $128.2 \pm 0.2 \mathrm{i}$ & $1232 \pm 0.8 \mathrm{~h}$ & $1232 \pm 1.6 \mathrm{~h}$ & $121.4 \pm 07 \mathrm{~h}$ & $121.7 \pm 16 \mathrm{~h}$ & $57 x$ \\
\hline
\end{tabular}

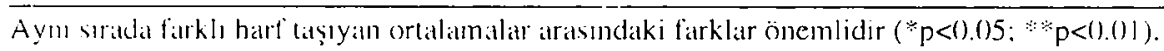


Tablo 4. Gruplatrda ortalama yumurta verimi ve yumurta ağırlığ de gogerleri (ortalaınat \pm standart hata).

rable 4. Mcan valucs of ege production and $\mathrm{cgg}$ weight in groups (mcan \pm standard error).

\begin{tabular}{|c|c|c|c|c|c|c|c|c|}
\hline Hallia & $\begin{array}{c}1 \\
\text { Kontrol }\end{array}$ & $\begin{array}{c}2 \\
\text { Enzim }\end{array}$ & $\frac{3}{\text { Antibiyotik }}$ & $\begin{array}{l}4 \\
\text { Probiyotik }\end{array}$ & $\begin{array}{l}5 \\
\text { Enzim + } \\
\text { antibiyotik }\end{array}$ & $\begin{array}{l}\quad 6 \\
\text { Antibiyotik + } \\
\text { probiyotik }\end{array}$ & $\begin{array}{c}7 \\
\text { Enym + } \\
\text { probiyouth }\end{array}$ & $\mathrm{F}$ \\
\hline \multicolumn{9}{|c|}{ 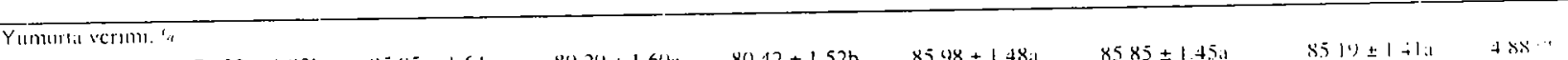 } \\
\hline $26-29$ & $7923 \pm 1.83 \mathrm{~h}$ & $85.05 \pm 1.64: 1$ & $89.29 \pm 1.60 \mathrm{al}$ & $8(0) 42 \pm 1.52 h$ & $8.5 .98 \pm 1.48 .1$ & $85 \times 5 \pm 1+5 \mathrm{a}$ & $8519 \pm 1=1: 1$ & 4.5 \\
\hline 301.33 & $7833 \pm 1530$ & $87.41 \pm 1.57 \mathrm{~h}$ & $91.85 \pm 1.1 .5 \mathrm{ih}$ & $80.19 \pm 2060$ & $91.30=15.4 \mathrm{ith}$ & $02.22=1.22 \mathrm{a}$ & $y(1): \pm i+i, a b$ & $|+4|=$ \\
\hline .34 .37 & $8 \% 111 \pm i .46 h$ & $915: \pm 125 i 1$ & $9(0.6 \mathrm{~B} \pm 1.07$ *ath & $90.68 \pm 1.39 \mathrm{ah}$ & $y 2.46 \pm 1.3311$ & $92.72 \pm 1.16 .1$ & $91-01 \pm 1(12 a$ & $22^{-}$ \\
\hline $3 x-41$ & $9167 \pm 0.9 x$ & $91.111 \pm 1.114$ & $90.61 \pm 0.99$ & $88.49 \pm 1.12$ & $y 1.27 \pm 11.90$ & $9074 \pm 106$ & 4251103 & 15 \\
\hline$+2-45$ & $925 y \pm 1.25: 1$ & $93.65 \pm 0191 \mathrm{il}$ & $91.14 \pm 1.2$ mah & $x 8.3 h \pm 1.22 \mathrm{~h}$ & $92.72 \pm 1.172 \mathrm{il}$ & $92010 \pm \pm 104.1$ & $91 \div 1 \pm 1203,15$ & $2.2+1$ \\
\hline $26-4.5$ & $x .5 .5() \pm 10.92 \mathrm{~h}$ & $89.89 \pm 0.85$ & $40.69 \pm 0.80 \mathrm{a}$ & $87.20 \pm 1.04 \mathrm{~h}$ & $y 1.01 \pm 0.6 \%$ & $x y 7 y \pm 117 x_{i 1}$ & (4) $2 x \pm 11: 3 ; 1$ & $5(y)$ \\
\hline \multicolumn{9}{|c|}{ Yumurlit itgrlığ. g } \\
\hline $26-.29$ & $5 \times 21 \pm 11.3 \%$ & $61.04 \pm 0.50)$ & $59.07 \pm 0.39 \mathrm{~cd}$ & $57.73 \pm 0.44 d$ & $5970 \pm 0.56 h$ & 6()$\times 8 \pm 1)+4 y_{12}$ & 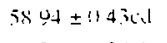 & y. $26 \%$ \\
\hline $.31-3.3$ & (x) $4 x \pm 0.5 x$ & $6.3 .28 \pm 0.54: 1$ & $62.06 \pm 0148 \mathrm{ah}$ & $61.32 \pm 0.42 \mathrm{bc}$ & $61.26 \pm 0.72 \mathrm{hc}$ & $62.20 \pm 0.51 \mathrm{ath}$ & $6271 \pm 113$ s.at & $318:$ \\
\hline$\therefore 4-37$ & $62.90=0.55 \mathrm{ab}$ & $6+44 \pm 0.59 \mathrm{a}$ & $63.53 \pm 0.53 \mathrm{a}$ & $62.80 \pm 0.34 a$ h & $61.78 \pm 0.68 \mathrm{~h}$ & $63.115 \pm 0.55 \mathrm{ath}$ & $6.3 .94 \pm 11360: 1$ & 272 \\
\hline $3 x+1$ & $6.354 \div 11.54 \mathrm{~h}$ & $6.5 .50 \pm 0.5 \% \mathrm{a}$ & $64.26 \pm 0.56 \mathrm{ab}$ & $0.3 .06 \pm 0.45 \mathrm{bc}$ & $61.95 \pm 0.50$ & $6+23=0.4 \mathrm{Bih}$ & $64.55=19.41546$ & $5 ? 1 \cdots$ \\
\hline+2.45 & $64.5 x=0.51 \mathrm{hh}$ & $(x 6.51 \pm 06.5 \mathrm{al}$ & $63.99 \pm 0.48 \mathrm{~h}$ & $6.3 .74 \pm 0.52 \mathrm{~h}$ & $0.3 .86 \pm 0.6 \mathrm{sh}$ & $6+6.3 \pm 0.54 \mathrm{~h}$ & $64.53=01401$ & $\therefore 74$ \\
\hline $20-45$ & $6.20 .3 \pm 112600$ & $0.120=0.27 \mathrm{al}$ & $62.53 \pm 0.24 \mathrm{hc}$ & $61.70 \pm 0.23 \mathrm{~d}$ & $61.69 \pm 0.2 y \mathrm{~d}$ & $63.101 \pm 0(1) 24 \mathrm{~h}$ & $6205=1121 \mathrm{~h}$ & 1255 \\
\hline
\end{tabular}

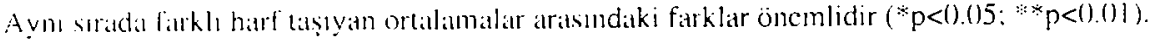

Tablo 5. Gruplarda ortalama yemden yararlamma degerleri (ortallama \pm standart hata).

Tible 5. Mcill valucs of feed efficiency in groups (mean \pm standard error).

\begin{tabular}{|c|c|c|c|c|c|c|c|c|}
\hline Hittia & $\begin{array}{c}1 \\
\text { Kontrol }\end{array}$ & $\begin{array}{c}2 \\
\text { Enzim }\end{array}$ & $\begin{array}{c}3 \\
\text { Ancibiyotik }\end{array}$ & $\begin{array}{c}4 \\
\text { Probiyotik }\end{array}$ & $\begin{array}{l}\quad 5 \\
\text { Entim + } \\
\text { antibiyotik }\end{array}$ & $\begin{array}{l}\quad 6 \\
\text { Antibiyouk + } \\
\text { probiyotik }\end{array}$ & $\begin{array}{l}7 \\
\text { Ensin }+ \\
\text { probiyolik }\end{array}$ & $F$ \\
\hline \multicolumn{9}{|c|}{ 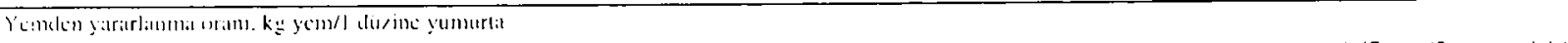 } \\
\hline $26 \cdot 29$ & $17.1 \pm 11.13$ & $172 \pm 0.155$ & $1.62 \pm 0.014$ & $1.61 \pm 0.07$ & $1.64 \pm 001$ & $|60| \pm 00 \mid$ & $1.0^{-} \pm(1, i) ?$ & $! 111$ \\
\hline $3(1-33$ & $177 \pm 0.11$ & $1.60 \pm 0.044$ & $1.65 \pm 0.017$ & $1.83 \pm 0.13$ & $1.54=0104$ & $|5| \pm 0.07$ & $1: i n=1111$ & 2 it \\
\hline $3+37$ & $172 \pm 0.013$ & $1.70 \pm 0.13$ & $1.72 \pm 0.016$ & $1.73 \pm 0.04$ & $1.68 \pm 0112$ & $10.4 \pm 13.15$ & $109 \pm(1011$ & 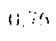 \\
\hline $3 \times .41$ & $1.78 \pm 0.014$ & $1.70 \pm 0.08 x$ & $1.75 \pm(1.1) 3$ & $1.72 \pm 0.07$ & $1.66 \pm(1.1) 2$ & $161 \pm 13(14$ & $1.5 n \pm 11: 113$ & $2 . \mathrm{K}$ \\
\hline $4 ?+45$ & $1.73 \pm 0.04$ & $1.73 \pm 0.10 .3$ & $1.74 \pm 0.39$ & $1.76 \pm 0.04$ & $1.64 \pm 0.0 .03$ & $167 \pm 01114$ & $170 \pm 0112$ & $11 \times 5$ \\
\hline 26.45 & $175 \pm 0015$ & $1.70 \pm 0.03$ & $1.70 \pm 0.311$ & $1.70 \pm 0.07$ & $1.62 \pm 01.02$ & $162=0.018$ & $162 \pm 1112$ & 21.3 \\
\hline \multicolumn{9}{|c|}{  } \\
\hline $26-2 y$ & $2.49 \pm 01.17$ & $2.33 \pm 008$ & $2.29 \pm 0.06$ & $2.33 \pm 0.09$ & $2.29 \pm 0.114$ & $2.19 \pm 11.111$ & $2.33=(11) 2$ & 136 \\
\hline $3(k-33$ & $24+ \pm 0.16$ & $219 \pm 0.144$ & $2.22 \pm 0.06$ & $2.49 \pm 0.18$ & $2.199 \pm 0.14$ & $20.3 \pm 0.11$ & $207 \pm 001$ & 314 \\
\hline $34-37$ & $2.2 \mathrm{~K} \pm(1.1) 4$ & $2.20 \pm 00$. & $2.27 \pm 01.12$ & $2.30 \pm 0.104$ & $2.26 \pm(0.1) 3$ & $2.16 \pm 01106$ & $2.20 \pm \pm 110 !$ & 1175 \\
\hline $3 x+1$ & $2.33 \pm 0.116$ & $2.17 \pm 11.11$ & $2.27 \pm 01113$ & $2.28 \pm 0.10$ & $2.2 .3 \pm 11.113$ & $2 .(16)=0.034$ & $\therefore 10=414$ & $2 i$ \\
\hline $42-45$ & $2.24 \pm 0.03$ & $2.16 \pm 10.114$ & $2.27 \pm 0.119$ & $2.30=0.06$ & $2.14 \pm 11.03$ & $216 \pm 11016$ & $\therefore 14=111 \mathrm{int}$ & $1 \%$ \\
\hline $26-4.5$ & $236=01.118$ & $2.21 \pm 0.114$ & $2.26 \pm 11,01$ & $2.30 \pm 0.09$ & $2.19 \pm 1103$ & $215 \pm 0.01$ & $\therefore 1+=$ & $27 x$ \\
\hline
\end{tabular}

Gruplar allatsundaki fark inemsizdir ( $p>(1.015)$.

Tablo 6. Gruplardal yumurta kal itesine ail ortalama de ğ̣ erler (ortalama \pm standart hata).

Table 6. Mcinl vilucs of ege quality characteristics in groups (mean \pm standard cror).

\begin{tabular}{|c|c|c|c|c|c|c|c|}
\hline $\begin{array}{c}1 \\
\text { Kontrol }\end{array}$ & $\begin{array}{c}2 \\
\text { Enzinn }\end{array}$ & $\frac{3}{\text { Antibiyotik }}$ & $\begin{array}{l}4 \\
\text { Probiyorik }\end{array}$ & $\begin{array}{c}5 \\
\text { Enzim }+ \\
\text { antibiyotik }\end{array}$ & $\begin{array}{l}\quad 6 \\
\text { Antibiyotik + } \\
\text { probiyouk }\end{array}$ & $\begin{array}{l}7 \\
\text { Eurim }+ \\
\text { poobivouk }\end{array}$ & $F$ \\
\hline \multicolumn{8}{|l|}{ 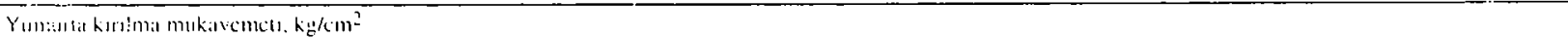 } \\
\hline $3.46 \pm(1)(18: 11$ & $3.13 \pm 0.09 \mathrm{bc}$ & $3.22 \pm 0.0 \times a t c$ & $2.91 \pm 0.08 \mathrm{~h}$ & $3.3 .3 \pm 1) .618 . k$ & $3.34 \pm 01199: 16$ & $. .37 \pm 0104 y_{i 1 i}$ & $+i_{1} \ldots$ \\
\hline \multicolumn{8}{|l|}{ Y'unutrlal aki indaksi } \\
\hline$\therefore 25 \pm 026$ & $7.98 \pm 01.23$ & $7.9 .5 \pm 0.25$ & $7.40 \pm 0.25$ & $8.24 \pm 0.24$ & $814 \pm 026$ & $762 \pm 1123$ & $1 \% 4$ \\
\hline \multicolumn{8}{|l|}{ Ymmurlia virn melcksi } \\
\hline $45.64 \pm 1148$ & $46.07 \pm 1036$ & $45.30 \pm 0.36$ & $44.93 \pm 0.34$ & $46.04 \pm 0.41$ & $45.90 \pm 0.31)$ & $15: 4 \pm 1 / 4$ & $11 x$ \\
\hline \multicolumn{8}{|l|}{ Yumurla Hatlöl hirimi } \\
\hline $77.13 \pm 118$ & $75.59 \pm 1.17$ & $75.54 \pm 1.31$ & $73.14 \pm 1.32$ & $76.85 \pm 1.163$ & $77.188 \pm 11.94$ & $7+60=; 26$ & 156 \\
\hline 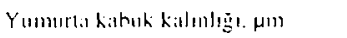 & & & & & & & \\
\hline $396.9 \pm 2.76: 1$ & $38112 \pm 2.41 \mathrm{~h}$ & $396.1 \pm 3.43: 1$ & $38018 \pm 392 h$ & $3958 \pm 336: 1$ & $380 y \pm 3.23 \mathrm{a}$ & $3 y 4 ! \cdot 2 \times 2.1$ & $5: 1 \times$ \\
\hline
\end{tabular}

$n=(0)$

Aym surada larklı harf laşyatu ortalamalar arasindaki farklar önemlidir $\left({ }^{* *} p<0.01\right)$. 
dă hir farklılık oluşturmamuşư. Yapılan çalışmada elde edilen hulgulat. yumurla lavuğu rasyonlannda enzim $(6$. 10.18.22.37), probiyolik (11.41), antibiyotik (37), enzinıt probiyotik (41), enzimtantibiyotik (37), antibiyotik+probiyotik (11) kullamılnasmm canlı ağ bir ctkisinin olnadığını bildiren araşııma sonuçlarını desleklemektedir.

Yaplan araşırma süresince gruplarda ölüm göz lennentiştir. Benzer olarak yapılan bazı araştırmalarda yumırta tavuğ̣u rasyonlannda enzim (18,41), probiyotik (5.11.41), enzim+probiyotik (41), antibiyotik+probiyotik (11) bulunmasmm ölüm oranmu etkilemediği bildirilmişiir.

Rasyonlara enzim, probiyotik ve antibiyotiğin ayr ayrı ya da birlikte ilavesi yumurta tavuklarında kontrol grubuna göre yem tiiketimi bakınından istatistik açıdan bir larklılık yaratmamışur. Araşurma bulguları, rasyoulara en im $(8,16.18 .21,37)$, probiyolik $(26,27,41)$, anlibijotik (37), en/int+probiyotik (41), cn/intantibiyotik (37) ilavesinin yumurta tavuklarmda yem tüketimini etkilenkediğ şcklindeki literatür bildirişleriyle uyum içerisindedir.

Arpa ve buğday ağılıklı yumurta tavuğu rasyonlarma probiyotik ilavesi yumurta verimini etkilememişii. Flde edilen araşluma bulgusuna benzer olarak bazı araşirıcılar $(5.11,27,41)$ rasyonlara probiyotik ilavesinin yumurta veriminde farklılık yaratmadığm rapor etmişlerdir. Mohan ve ark. (26) rasyonlara $100 \mathrm{mg} / \mathrm{kg}$ probiyotik ilivesinin yumurta verinini \% 5 düzeyinde artururken 150 $m g / k g$ probiyotik ilavesinin yumurta veriminde $\% 2$ diizeyinde bir diişmeyc yol açuğ lavagu rasyonlarma Lactobacillas külturunuin ilave edilmesinin ise yumurta verimini \%3.03 düzeyinde bir artıs ile olumlu yönde etkilediği belirtilmiştir (24).

Yapılan araşurmada arpa ve buğday ağırlıklı rasyonlara enzim, antibiyotik, enzimtantibiyotik, antibiyolik+probiystik ve enzint+probiyotik ilavesi yumurta verimini kontrol grubuna göre önemli derecede arttırmıştır. Benzer olarak. Jamroz ve ark. (21) arpa veya bugdaya dayalı rasyonlara enzim ilavesinin yumurta verimini önemli derecede arturdığm kaydemişlerdir. Araşurma bulgularundan farklı olarak bazı araşurmalarda rasyonlara enzim (3,7.13,23,29). antibiyotik (37), enzimtprobiyotik (41), emzintantibiyotik (37), antibiyotik+probiyotik (11) ilavesinin yumurta tavuklarmda yumurta veriminde farklılık yaramadığ bildirilnıiştir.

Arpa ve buğday ağırlıklı yunurta tavuğu rasyonlarına enzinı. antibiyotik+probiyotik ve enzim+probiyoliğin ilavesi yumurta ağılığını önemli derecede $(p<0.01)$ artturmuşur. Rasyonlara amtihịotik. probigolik ve enzimtantibiyotik jlavesi ise yumurla ağ tatistik açıdan bir farklılık yaralmamışur. Yapılan barı araştırmalarda rasyonlara prohiyotik (27) ve encim (22) ilavesinin yumurta ağırlığms arlurd!ğ $(p<0.05)$ hildirimiştir. Bazı araşırneılar ise yumurta lavuğg rasyonlarma enzim (15,16.21,23.29). probijolik (5.25), an tibiyotik (37) ve enrimtantibiyolik (37) ilavesmin

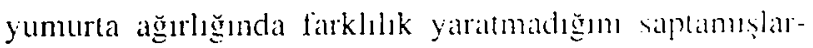
dir.

Yapilan araşturmada rasyonlara enzmm ilaves so-

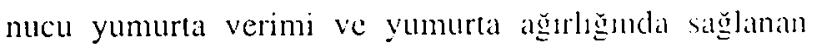
artış. kullanılan cnzimin ycmlerin sindirilebilitlig̣nin anttırmasına bağlanabilir $(8,14,37)$. Bazı araşırıcılar (9.20). 38) arpadaki visko\%. $\beta$-glukanlaran hağırsakla neden olduğu olumsuz etkinin enzim kullimm ile araldiğ bum bildirmişlerdir.

Yirmi haftalık araştırma suresince rasyonlarda enzim. probiyotik ve antibiyotiğgn ayn alyn veyal birlikle kullanılmaları, gerck 1 diizine yumurla jçin lükelilen yen miktarı ve gerekse $1 \mathrm{~kg}$ yumurı için tiiketilen ycm miktarı bakımından farklılık yaratmamuşlır. Bàı araşuncılar yumurta lavuklarsnda yemden yararlanma orammen rasyonlara cnzin (13.22.23.29,37). probiyouk (11.19.27.41). cnzim+probiyotik (41). encimtantibiyotik (37). antibiyotik+probiyotik (11) ilavesinden etkilenmediğini. haziları da cnzim $(2,7,35,39)$ veya probiyolik (24.26) jlavesinden olumlu yönde etkilendiğini kaydetmişlerdir.

Araştırmada rasyonunda conzim veya probigntiğ kapsayan gruplarda yumurta kirlma mukavemels ve yumurta kabuk kalınlığ1 diğer gruplardakinden diișiik bulunmuştur $(p<0.01)$. Bazı araştuructar yumurta lavuğu rassyonlarma enzin ve/veya probiyotik ilavesinin yumurla

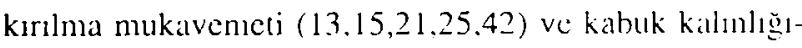
nı $(1,13,21,27,42)$ etkilemedi⿹̆巳ni kaydetmişlerdir. Sirvydis ve ark. (32) ise enzim ilavesinin yumurla kabuk kalınlığını arturdığın bildirmişleredir.

Yapılan araşurmada rasyonlarda enzim. probiyolik ve antibiyotiğin ayrı ayrı ya da birlikte kullanulmass yumurta akı indeksi, yunurta sarı indeksi ve Halugh birimi bakımından farklılık yaramamışlur. Bulgulall bazı arastırma sonuçlarına (16.27.30.31.42) ben\%erlik göstermekledir.

Arpa-buğday ağırlıklı rasyonlara cnzim, probiyolik ve antibiyotiğin ayr ayn veya birlikte katılnaları. çatlak kırık yumurta sayısı, kirli yumurta sayısı ve yumurtadi kan lekesi bakımından bir farklılık yaratmamışur. Benze olarak Berg (6), arpaya dayalı rasyonlara cnzim ila vesinin yumurtada kan lekesi yuizdesini etkilemedjğini bildirmiştir. Buna karşılık Hamilton ve Proudfoot (18). 
arpa ağıllkl rasyonlara glukanaz ilavesinin 196 grïnde 1oplanan yumurtalarda kan lekesi oluşumunu arturdığını kaydetmişlerdir $(p<0.05)$. Francesch ve ark. (16), arpa ve ayçiçeğ küspesine dayalı rasyonlara enzim kompleksi ilaresinin ilk dört haltada kirli yumurta sayssm $\% 14.3$ cien $\% 12.3$ e azaltuğm $(p<0.05)$ fakat daha sonra isce elkilemediğini bildirmişlerdir. Bazı araştırıcılar (3.22.29) arpa veya bugdaya dayalı rasyonlara enzim ilavesinin kirli yumurla sayısında farklılı yaratmadığnı kaydemişlerdir.

Araşurnalarda farklı sonuçlarm elde edilmesi, kullamban hayvanlarm yassına ve genetik farklılıklarma. yem madkelerinin yapılanndaki nişasta tabiatında olmayan polisakkaritlerin yapıss ve düzeyine, rasyonların farklı yem maddelerinden oluşmasına ve besin madde bilesininin larklı olmasına bağlanabilir $(1,22,33)$.

Sonuç olarak, arpa ve buğglay ağılıkh rasyonlara probiyotiğin cnzim veja antibiyotik ile birlikte ilavesi yumurta tasuklurinda yemden yararlanma oranı ve bazı yumurta kalite özlljklerini olumsu\% yönde etkilemeden yumurla ağ

\section{Kaynaklar}

1. Abduilrahim SM, Haddadin MSY, Hashlamoun EAR, Robinson RK (1996): The influence of Lactobacillus acidrphilus and baciracin on laver performance of chickens and chrolesterol coment of plasma and egin yolk. Brit Poulury Sci. 37. 341-346.

2. Nimonen EMJ, Nasi M (1991): Replacement of barley by oats and enayme supplementation in diets for laying hens. 1. Performance and balance trial results. Acta Agric Scind. 41. 179-192.

3. Al Bustany Z, Elwinger $\mathbf{K}$ (1988): Whole grains. unprocessed rapeseed and $\beta$-slucanase in diets for laving hems. Swed J Agric Res. 18. 31 -40.

4. AOAC (1984): Official Methods of Anatysis of the Association of Official Analirical Chemists. $14^{\text {th }}$ ed. Inc. Arlington. Virginial.

5. Balevi ' 1 , Uçan LS, Coşkun B, Kurtoğlu v, Çetingül IS (2(0)1). Effect of diefary probiotic on performance and humoral immune response in layer hens. Bril Poultry Sci. 42. $456-461$.

6. Berg IR (1959): Enzyme supplementation of barley diets for laving hens. Poultry Sci. 38. 1132-1139.

7. Brenes $\Lambda$, Guenter $W$, Marquardt RR, Rutter BA (1993): liffect of $\beta$-ylucanase/pentosanase enzyne supp. tementation on the performance of chickens and laving hens fed wheal. barter: naked oats and re diers. Can J Anim Sci, 73, $941-951$.

8. Brufau J, Cos R, Perez-Vendrell A, Esteve-Garcia $\mathbf{E}$ (1994): Performance of laving hens as affected by the supplementation of a barley-based diet with a crade enzyme preparation from Trichoderma viride. Can J Anim Sci, 74. 129-133.
9. Campbell GL, Rossnagel BG, Classen HL, Thacker P'A (1989): Genotypic and envirsmental differences in sarrac viscosity of barley and their relationshup in its murtite value for broiler chickens. Anim Feed Sci Technol. 26. $221-230$.

10. Card LE, Neshein MC (1972): Poultwe Pruductum. Ifti ed. Lea and Fchiger. Philiadelphiat.

11. Cerniglia G.J, Goodling AC, Hebert JA (1983): the tes ponse of lavers a feeding Lachohacilless formentaturn pro. duct.5. Poultry Sci. 62.1399

12. Classen HL, Bedford MR (1991): The ase of entrymes w" improve the nuritive value of proultra ferds. 95-116. In: W Harcsign. DJA Cole (Eds), Recent Advances in Animal Nutrition. Butterworths-Heinemann I.ld. Oxtiord.

13. Çiftçi İ, Yenice E, Gökç̧eyrek D, Öztürk li (|y)7). Alpa be buğday iferen larak remlerinde ensim kullamm

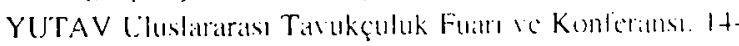
17.5.1997. 1stimbul. Bildiriler. 199-211.

14. Edney M.J, Campbell GL, Classen HI. (1989): The effect of B-glacanase supplemenuation on mutremt disersibilion. and growth in broilers given diets contciming harley: nat grouts or wheat. Anim Feed Sci Tochnol. 25. 193-213.

15. Ergün A, Yalçın S, Çolpan İ, Muğlalı H (199) 3): Yüunurka

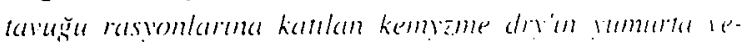

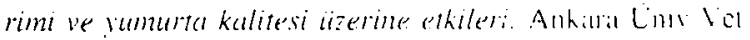
Fatk Derg. 40. 371-378.

16. Francesch M, Perez-Vedrell A, Esteve-Garcia E, Brufau J (1995): Ensyme supplementiaion of a haste? and sunflower-hased diet on laving hen performance. J Appl Poultry Res, 4. 32-40.

17. Frapin D, Geraert PA, Uzu G (1997): VSP-enzame imp-

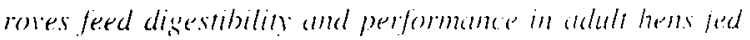
wheat hased diets. $11^{\text {la }}$ Europan Symposium on Poultry Nutrition. August 24-28. Fuaborg-Derimark. World: Poultry Science Association. Proced dings. 4\$1-483.

18. Hamilton RMG, Proudfoot FG(1993): Elfects of dietery barley level on the performance of Leshom hens. Cill I Anim Sci. 73, 625-634.

19. Hargis P, Creger $\mathbf{C R}$ (1978): Luctohacillus fermentution product in laving hen ratoms. Poultry Sci. 57. 1103

20. Hesselman $\mathbf{K}$ (1989): The use of entames in pondlut diets Procecdings of the $7^{\text {th }}$ European Symposium an Poultry Nutrition. Lloret de Mar, Spam, $31-45$.

21. Jamroz D, Skorupinska J, Orda .J. Wilicgkicwic\% A (20)()): Use of wheat. barley or triticale stains in mivares supplemented with carbohydrases derited from Tric. hoderma !ongibrachicalum for lavings hen. XXI World's Poultry Congress. 20)-25 August 2000, Montrcil. Cillidia. p 4.14.

22. Jaroni D, Scheideler SE, Beck M, Wyatt $(: 1999)$ ): The effect of dietary wheal middlings and merme supp-

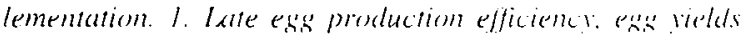
and eger composition in two struins of lesthom hens. Poultry Sci, 78, 841-847.

23. Karimi A, Scott TA, Bedford MR, Vikkhah $A$, Kanyah A, Yazdanparst R, Moradi M (20)(1): Evaluction of ent:yme. far source and level of supplementation in hulles bar. ley-hased diets fed of two strains of lavms hens. Proccedings of IX European Symposium on the Quality of 
Fegs and Egir Products. 9.12 September 200)1, Kuşadasi. Turtey. 157-162.

24. Krucger WI, Bradley JW, Patterson RH (1977): The intercation of gentian violet and Lactobacillus organisms in the diet of Leghom hens. Poultry Sci, 56. 1729

25. Iee KW (1999): Elfect of Aspersillus Orzae on Fecal Miconfloret. Egg Qualities and Natrient Metabolizabilities in Layers. MsD Thesis. Chungnam National University. Department of Animal Science. Chungnam.

26. Nohan B. Kadirvel R. Bhaskaran M, Natarajan $\Lambda$ (1095): Effect of probiontic supplementation on serumfolk cholesterol and on egin shell thickness in lavers. Brit Poultry Sci. 36, 799-8013.

27. Nahashon SN, Nakaue HS, Mirosh I,W (1996): Nutrient retentom and production parameters of Single Comb White Leshorn lavers fed diets with varing crude protein levels and supplemented with direct-fed microbials. Anim Fecd Sui Technol. 61, 17-26.

28. Nasi M (1988): Enarme supplementation of laying hen diets baned in harley and onss. 199-204. In: TP Lyons (Ed). Bintechnology in the Feed Industry. Allech Technical Publications, Nicholasville.

29. Polat C, Akyürek H, Konyalı A, Şenköylü N (1995): Supplementation of an enzime preparation to wheat and batey based diets fed to commercial brown lavers. WPSA Proccedings. $10^{\text {th }}$ Europcan Symposium on Poultry Nutrition. 15-19 October. Antalya-Turkiyc. 360-361.

30. Roberts JR, Ball $\mathbf{W}$ (2001): Feed enzymes in wheat-based diets and egon and egos shell quality in laying hens. Prococding:s of IX European Symposium on the Quality of Figgs and Egg Products, 9-12 September 20)(1) Kuşadast, rurkey. $145 \cdot 147$

31. Schang M.J, Azcona JO (1998): Performance of laying hens fed a com-sunflower meal diet supplemented with inzimes. 4054(19. In: TP Lyons. KA Jasques (Eds). Biwechnology in the Feed Industry. Procecdings of Altech's Fourteonth Annual Symposium. Notlingham. University Press.

32. Sirvydis V, Vencius D, Gudavaviciute D, Sabalionyte $R$ (2)(n): liffect of multiensime compositions on egg shell quality of laving hen.s. XXI World's Poultry Congress. 2025 August 2000. Montreal. Canada. p 20.10!
33. Stutz MW, Lawton GC (1984): Lffects of diet and an-

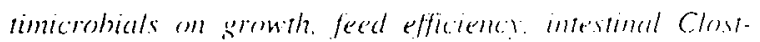
ridium perfingens and ileal weight of brobler chacks $P_{1}$ ultry Sci. 63. 20136-20142.

34. Sümbüloğlu K, Sümbüloğlu V (1945): Bivrsiskntrik, 6. Baskı. Özdemir Yayıncıllk. Ankilra.

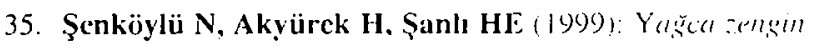

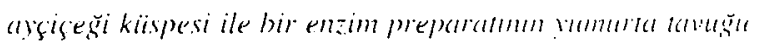

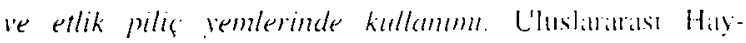
vanchlik'99 Kongresi. 21-24 l:ylial 1999. L/mire. +38-4+3



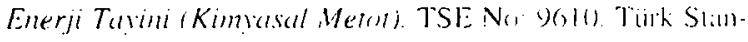
dartları Institissii. Ankilra.

37. Vukic Vranjes MV, Wenk C (1990): Inlluence of Tirshoderma viride enatme complex on mutrtemt unlization and performance of laving hens in diets with and withom anthiotic supplementation. Poultry Sci. 75. 5.51-5.55.

38. White WIs, Bird HR, Sunde ML., Marlett .J/ 1983 !

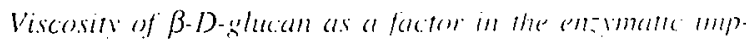
rovement of batey for chicks Poultry Sol, 62. $553-802$

39. Wyatt CL. Goodman T (1993): Litilisemon of feed entymes in laving hen rations. J Appl Poull Res. 2. 68-74

41). Yalçın S, Çiftçi İ, Önol AG. Yılmaz $\Lambda(1996)$. Yem kutht maddelerinde gelismeler. 3. Uluslararast $\mathrm{Ycm}$ Kongren ve Yom Scrgisi. 1-3 Nisinn 1996. Ankanal. Yom Sambivicilori Birligit. 23-47.

41. Yalçın S, Kahraman $Z$, Gürdoğan T, Dedeoğlu HE, Ko-

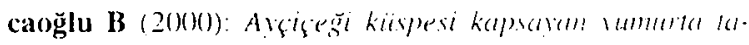


iizerine elkssi. Tavukçuluk Arașumbi Derge. 2(1), 25-32.

42. Yalçın S, Kahraman Z, Yalçın S, Dcdcoğlu HE (20)(0)):

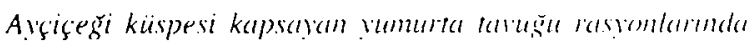
enzin ve prohigonik kullanmm. 2-Yumurta kalitesi iiscrine ekkisi. Tarvukçuluk Araşurma Derğ. 2(2). 19-24.

Gelis tarihi: 14.11.200) / Kathul tarthi: 10.1.2(1)2

Yåş̧ma adresi:

Prof.Dr. Sakine Yalçln

Ankara Universitest. Veteriner Faküles

Hayvan Besleme ve Beslenme Hastaliklant

Anabilim Dal, Dtskapt. Ankara 